\title{
TEXTURA INSTRUMENTAL DE QUEIJO PETIT-SUISSE POTENCLALMENTE PROBIÓTICO: INFLUÊNCIA DE DIFERENTES COMBINAÇÕES DE GOMAS ${ }^{1}$
}

\author{
Larissa Yukie MARUYAMA², Haíssa Roberta CARDARELLI², \\ Flávia Carolina Alonso BURITI², Susana Marta Isay SAAD ${ }^{2, *}$
}

\begin{abstract}
RESUMO
O efeito de diferentes combinações de gomas sobre os parâmetros de textura instrumental de queijo tipo petit-suisse probiótico foi avaliado. Queijos petit-suisse foram produzidos utilizando-se massa-base de queijo quark preparada com o starter Streptococcus thermophilus e os probióticos Lactobacillus acidophilus e Bifidobacterium longum. Três formulações de queijo petit-suisse foram preparadas, a partir de massa-base de queijo quark adicionada de 0,75\% do produto final da mistura de gomas - xantana (X), carragena $(\mathrm{C})$, guar $(\mathrm{G})$, pectina $(\mathrm{P}): \mathrm{F} 1=2,5 \mathrm{X}: 2,5 \mathrm{C}: 5 \mathrm{G}$; F2 $=2 \mathrm{X}: 3 \mathrm{C}: 5 \mathrm{P}$; F3 = 5C:5G. Os parâmetros avaliados após 1, 7 , 14 e 21 dias de armazenamento do produto a $4 \pm 1^{\circ} \mathrm{C}$ incluíram a contagem de probióticos, a textura instrumental, o pH e a umidade. As populações de probióticos mantiveram-se acima de 6,40 log UFC/g para L. acidophilus e de 7,30 log UFC/g para B. longum. Houve diferença significativa entre as formulações $(\mathrm{p}<0,05)$ para todos os parâmetros de textura, exceto a firmeza de $\mathrm{F} 1$. O pH e a umidade apresentaram comportamento semelhante para as três formulações. Dentre as formulações estudadas, F1 foi considerada a melhor, por sua firmeza mais estável durante o período de armazenamento.
\end{abstract}

Palavras chaves: Lactobacillus, Bifidobacterium, alimento funcional, firmeza, laticínio, hidrocolóides.

\section{SUMMARY}

INSTRUMENTAL TEXTURE OF PROBIOTIC PETIT-SUISSE CHEESE: INFLUENCE OF DIFFERENT COMBINATIONS OF GUMS. The effect of different combinations of gums over texture parameters of probiotic petit-suisse cheese was evaluated. Petit-suisse cheeses were produced using Quark cheese-base prepared with the starter Streptococcus thermophilus and the probiotics Lactobacillus acidophilus and Bifidobacterium longum. Three formulations of petit-suisse were prepared, using the quark cheese-base added of $0.75 \%$ of the final product of the mixture of the hydrocolloids xanthan gum (X), carrageenan gum (C), guar gum (G), pectin (P): $\mathrm{F} 1=2,5 \mathrm{X}: 2,5 \mathrm{C}: 5 \mathrm{G} ; \mathrm{F} 2=2 \mathrm{X}: 3 \mathrm{C}: 5 \mathrm{P} ; \mathrm{F} 3=5 \mathrm{C}: 5 \mathrm{G}$. Parameters evaluated after 1, 7, 14, and 21 days of storage of the product at $4 \pm 1^{\circ} \mathrm{C}$ included microbial counts of probiotic microorganisms, instrumental texture parameters, $\mathrm{pH}$ and moisture. Probiotic counts were always above $6.40 \log \mathrm{CFU} / \mathrm{g}$ for $L$. acidophilus and above $7.30 \log \mathrm{CFU} / \mathrm{g}$ for B. longum. The formulations were significantly different $(\mathrm{p}<0.05)$ for all the texture parameters, except for firmness of $\mathrm{F} 1$. The $\mathrm{pH}$ and the moisture were similar for the three formulations. F1 was considered the best formulation, due to its more stable firmness during storage.

Keywords: Lactobacillus, Bifidobacterium, functional food, firmness, dairy product, hydrocolloids.

\section{1 - INTRODUÇÃO}

A exigência por alimentos com composição nutricional balanceada e que possam oferecer benefícios adicionais à saúde é manifestada intensamente pelos consumidores atuais. O queijo petit-suisse, desenvolvido por Charles Chervais em 1850, é produzido com leite desnatado e adicionado de creme, de consistência cremosa, e sua massa é obtida pelo processo de coagulação mista, podendo ser adicionado de condimentos doces ou salgados [33]. No Brasil, o produto é consumido como sobremesa e dirigido principalmente ao público infantil. Tem boa aceitação e público crescente de consumo, embora tais índices ainda sejam pequenos, quando comparados aos de outros países [41]. No Brasil, a produção anual de queijo petit-suisse aumentou de cerca de $14.000 \mathrm{t}$ em 1991 para cerca de 22.000 t em 2001 e projetava-se um volume de 23 mil toneladas para o ano de 2002 [3].

\footnotetext{
${ }^{1}$ Recebido para publicação em 27/6/2005. Aceito para publicação em 28/4/2006 (001557)

${ }^{2}$ Departamento de Tecnologia Bioquímico-Farmacêutica da Faculdade de Ciências Farmacêuticas da Universidade de São Paulo (USP)

Avenida Professor Lineu Prestes, 580

CEP 05508-000 - São Paulo (SP)

E-mail:susaad@usp.br

*A quem a correspondência deve ser enviada
}

Os queijos petit-suisse nacionais são adicionados de gomas que interagem com as proteínas do leite, podendo resultar em alterações na estabilidade e consistência do produto final [12, 34]. A determinação de seu comportamento reológico é importante em avaliações de consistência e estabilidade, fornecendo informações sobre a estrutura do produto [35].

As gomas, também chamadas de hidrocolóides, são aditivos alimentares que têm função de espessar, estabilizar, encorpar, conferir viscosidade, elasticidade e dar a textura desejada ao alimento produzido $[8,40]$. Podem, ainda, ser utilizadas como substituintes de gorduras, já que a gordura é fundamental para os efeitos sensoriais e fisiológicos dos alimentos, contribuindo para o sabor, percepção no aparelho bucal, aparência, aroma, etc. [23, 30]. Adicionalmente, contribuem como substituintes de açúcar e como fontes de fibras em dietas, sendo freqüentemente empregadas em produtos alimentícios light [2, 40].

Alguns exemplos de gomas que são freqüentemente empregadas na produção de laticínios são: carragena, xantana, litesse, guar, jataí e derivados de celulose [40]. A goma carragena é um polímero de galactose solúvel em água com aplicação na indústria farmacêutica e alimentícia como agente gelificante e estabilizante; possui amplo histórico de 
emprego em laticínios, uma vez que interage de forma muito favorável com as proteínas do leite [10, 36, 45]; é solúvel em água quente e estabiliza bem suspensões de polpas de frutas. A goma guar é capaz de formar soluções viscosas com alta capacidade de retenção de umidade, estabiliza suspensões, evitando a dessora; é bastante empregada em produtos lácteos, sendo compatível para a utilização em conjunto com outros espessantes como, por exemplo, carragena e pectina [27].

A goma xantana funciona muito bem como estabilizante em produtos à base de água, já que é uma goma solúvel e altamente higroscópica; também possui comportamento pseudoplástico quando em solução, capaz de manter estáveis o pH, a maciez e a estética visual do produto [20]. A pectina é formadora de soluções gelificantes, com capacidade de retenção de água, estabilizando as suspensões aquosas, porém com baixa viscosidade aparente [17]; seu uso é favorável, uma vez que apresenta baixo custo de obtenção, sendo um dos espessantes mais economicamente viáveis do mercado.

As gomas são freqüentemente empregadas para conferir consistência macia e, ao mesmo tempo, efeito encorpado em produtos derivados de leite, como bebidas lácteas, iogurtes e queijos. Outra função muito importante da goma é conferir estabilidade em queijos, evitando que o soro se separe da massa e conferindo ao produto textura desejável. Diferentes hidrocolóides conferem texturas distintas e diferentes efeitos sobre a micro e macroestrutura do produto [18].

O desenvolvimento de um queijo tipo petit-suisse probiótico visa adicionar certas bactérias láticas capazes de exercer efeitos benéficos ao hospedeiro. Atualmente, a definição aceita internacionalmente para probióticos é que eles são microorganismos vivos que, administrados em quantidades adequadas, conferem benefícios à saúde do hospedeiro [11,32]. O mercado de laticínios probióticos tem crescido rapidamente na Europa e continua em plena expansão [37, 38]. A utilização conjunta de L. acidophilus e Bifidobacterium spp. tem sido estudada em leites e bebidas fermentadas [15, 44], iogurtes comerciais [39] e vários tipos de queijos [29]. Dentre eles, destaca-se o queijo fresco [1, 6, 7, 28, 29, 31, 42].

A dose mínima diária da cultura probiótica considerada terapêutica é de $10^{8}$ a $10^{9}$ UFC, correspondente ao consumo de 100 g de produto que contenha $10^{6}$ a $10^{7}$ UFC/g [22]. Tais concentrações de microorganismos probióticos viáveis devem ser mantidas constantes ao longo do armazenamento do produto [26].

A possibilidade de se desenvolver uma tecnologia que envolva a adição de culturas probióticas para a obtenção de um produto alimentício funcional com uma textura apropriada e boas perspectivas de aceitação pelos consumidores é bastante promissora. Sendo assim, o presente trabalho objetivou avaliar a influência de diferentes combinações de gomas sobre a textura instrumental de queijo petit-suisse fabricado com a adição das bactérias probióticas Lactobacillus acidophilus e Bifidobacterium longum, bem como acompanhar a viabilidade dessas culturas durante o período de armazenamento do produto a $4 \pm 1{ }^{\circ} \mathrm{C}$, e obter uma formulação que apresente perfil de textura instrumental sem variações significativas durante o armazenamento.

\section{2 - MATERIAL E MÉTODOS}

\section{1 - Material}

\subsection{1 - Culturas}

Foram empregadas as culturas probióticas Lactobacillus acidophilus LAC4, Bifidobacterium longum BL04 e a cultura starter Streptococcus thermophilus TA040 (Danisco, Dangé, França), todas liofilizadas do tipo DVS (Direct Vat Set).

\subsection{2 - Ingredientes para a formulação do queijo quark}

Foram utilizados leite pasteurizado (HTST) desnatado (Salute, Descalvado, Brasil, 18 L para cada produção), cloreto de cálcio $(0,25 \mathrm{~g} / \mathrm{L}$ leite $)$ e coalho bovino em pó Ha-la (Christian Hansen, Valinhos, Brasil, 5 mg/L leite).

\subsection{3 - Ingredientes para a formulação do queijo petit-suisse}

Para a produção do queijo petit-suisse, foram utilizados creme de leite tradicional esterilizado (Nestlé do Brasil Ltda., Araçatuba, Brasil), polpa de morango integral congelada sem conservantes (Maisa, Mossoró, Brasil), açúcar refinado União (Coopersucar-União, Limeira, Brasil), corante natural carmim de cochonilha (Plury Química, Diadema, Brasil), aroma natural idêntico ao de morango (Mylner, São Paulo, Brasil), goma xantana Rhodigel 80 (Rhodia, Melle, França), goma Carragena Texture FG 100T (Avebe do Brasil Ltda., São Paulo, Brasil), goma Grindsted ${ }^{\circledR}$ Guar 178-B (Danisco, Cotia, Brasil) e goma Pectina Genu ${ }^{\circledR}$ tipo 8002 (CP Kelco, Limeira, Brasil). As proporções de ingredientes adicionados para a produção das três diferentes formulações de queijo petit-suisse estudadas estão apresentadas na Tabela 1 .

TABELA 1 - Proporções (\%) de gomas empregadas nas diferentes formulações de queijo petit-suisse estudadas no presente trabalho

\begin{tabular}{lccc}
\hline \multirow{2}{*}{ Gomas } & \multicolumn{3}{c}{ Composição ${ }^{1}$ na formulação padrão ${ }^{2}$} \\
\cline { 2 - 4 } & F1 & F2 & F3 \\
\hline Xantana & $0,1875 \%(2,5)$ & $0,15 \%(2)$ & 0 \\
Carragena & $0,1875 \%(2,5)$ & $0,225 \%(3)$ & $0,375 \%(5)$ \\
Guar & $0,375 \%(5)$ & 0 & $0,375 \%(5)$ \\
Pectina & 0 & $0,375 \%(5)$ & 0 \\
\hline TOTAL & $0,75 \%(10)$ & $0,75 \%(10)$ & $0,75 \%(10)$ \\
\hline
\end{tabular}

${ }^{1}$ Proporções que totalizam $0,75 \%$ (10 partes) de goma em todas as formulações

${ }^{2}$ Composição padrão para todas as formulações: massa-base de queijo quark (63,9\%), polpa de morango (11,5\%), creme de leite $(13,72 \%)$, açúcar $(10 \%)$, corante $(0,08 \%)$ e aroma $(0,05 \%)$ 


\section{2 - Métodos}

\subsection{1 - Processamento do produto}

O processamento do queijo quark probiótico foi desenvolvido experimentalmente no Laboratório de Tecnologia de Alimentos do Departamento de Tecnologia Bioquímico-Farmacêutica da Faculdade de Ciências Farmacêuticas da USP, São Paulo, com a adição dos microorganismos descritos no Item 2.1.1.

Após aquecimento do leite a $37^{\circ} \mathrm{C}$, o cloreto de cálcio foi adicionado e, após uma rápida homogeneização, as culturas probióticas L. acidophilus (3\% m/v) e B. longum $(2 \% \mathrm{~m} / \mathrm{v})$ e a cultura starter $\mathrm{S}$. thermophilus $(5 \% \mathrm{~m} / \mathrm{v})$ foram adicionadas, seguidas de uma nova homogeneização do leite. O coalho, previamente diluído em $50 \mathrm{~mL}$ de água fervida e resfriada, foi adicionado quando o leite atingiu $\mathrm{pH}$ entre 6,3 a 6,5, seguido de homogeneização. Após a coagulação ( $\mathrm{pH}$ entre 5,6 e 5,8), a coalhada foi cortada e mantida em repouso por 15 min. Em seguida, a massa foi transferida para sacos de algodão previamente esterilizados, para a dessoragem em câmara a $5^{\circ} \mathrm{C}$ por $14 \mathrm{~h}$.

As diferentes formulações de queijo petit-suisse foram obtidas a partir de homogeneização do queijo quark com os respectivos ingredientes apresentados na Tabela 1. As combinações de gomas e respectivas percentagens utilizadas em cada formulação no presente trabalho foram escolhidas após a realização de 15 ensaios preliminares, com a utilização de um, dois ou três estabilizantes combinados em diferentes proporções.

Os estabilizantes testados incluíram gelatina e as gomas xantana, carragena, guar e pectina e as proporções de cada um deles variaram de 0,2 a $0,5 \%$. A gelatina conferiu às formulações testadas uma consistência semelhante a uma mousse, não condizente com a esperada para um queijo petit suisse e, portanto, sua utilização foi descartada. As proporções de gomas selecionadas para as três formulações estudadas no presente trabalho foram selecionadas de acordo com a capacidade espessante e de estabilização, de modo a evitar a posterior dessora dos queijos.

A manutenção da textura estável durante o armazenamento e a facilidade de homogeneização do produto, resultando em um produto mais uniforme e reduzindo a formação de grumos, também foram considerados para a escolha das combinações de gomas utilizadas neste trabalho [25]. Finalizada a homogeneização, o produto foi, então, embalado em recipientes plásticos com capacidade para 35 g, selados com tampa metálica e armazenado sob refrigeração $\left(4 \pm 1^{\circ} \mathrm{C}\right)$.

\subsection{2 - Períodos de amostragens}

Os queijos petit-suisse de cada produção (lote) foram utilizados para as análises do produto final (dia 1) e após 7, 14 e 21 dias de armazenamento. Em cada período de amostragem, pelo menos sete embalagens contendo queijo petit-suisse do mesmo lote e formulação foram utilizadas para as análises. Amostras de cinco embalagens foram utilizadas para as análises de textura e imediatamente utilizadas para as análises físico-químicas. Para as análises microbiológicas, porções de $25 \mathrm{~g}$ foram coletadas assepticamente de duas embalagens, após uma rápida homogeneização do queijo petit-suisse, dentro de cada embalagem, utilizando-se uma espátula previamente esterilizada.

\subsection{3 - Análises físico-químicas}

As determinações de $\mathrm{pH}$ dos queijos foram realizadas em Medidor de pH-Analyser Modelo 300M (Analyser Comércio e Indústria Ltda., São Paulo, Brasil), empregando-se um Eletrodo tipo Penetração modelo 2AO4 GF (Analyser). A umidade foi determinada a $70^{\circ} \mathrm{C}$, em estufa a vácuo modelo MA030/12 (Marconi, São Paulo, Brasil), a partir de amostras de $5 \mathrm{~g}$. As análises de $\mathrm{pH}$ e umidade foram realizadas em quadruplicata.

\subsection{4 - Textura instrumental}

A textura instrumental dos queijos foi determinada, em quintuplicata, através de teste de dupla compressão, em texturômetro TA-XT2 (Stable Micro Systems, Haslemere, Reino Unido), utilizando dispositivo cilíndrico de alumínio com $25 \mathrm{~mm}$ de diâmetro e realizando compressão de $1 \mathrm{~cm}$. A velocidade empregada foi de $1 \mathrm{~mm} \mathrm{~s}^{-1}$. As amostras cilíndricas foram retiradas do refrigerador momentos antes do teste. Os dados foram coletados através do programa Texture Expert for Windows - versão 1.20 (Stable Micro Systems).

\subsection{5 - Análises microbiológicas}

Foram monitoradas as contagens de Lactobacillus acidophilus e Bifidobacterium longum nos queijos petitsuisse. Decorridos os tempos de armazenamento descritos no Item 2.2.2, porções de 25 g de queijo petit-suisse (retiradas em condições de assepsia) foram homogeneizadas com $225 \mathrm{~mL}$ de água peptonada $0,1 \%$ (diluição $10^{-1}$ ), utilizando-se o Bag Mixer 400 (Interscience, St. Nom, França). Diluições decimais subseqüentes foram preparadas, utilizando o mesmo diluente.

Para a contagem de L. acidophilus, alíquotas de $1 \mathrm{~mL}$ de cada diluição das amostras foram transferidas para placas de Petri estéreis. Em seguida, foi adicionado ágar DeMan-Rogosa-Sharpe (MRS) modificado, preparado como meio basal contendo maltose, de acordo com o INTERNATIONAL DAIRY FEDERATION [19]. Para a contagem de $B$. longum, foi adicionado ágar MRS acrescido de propionato de cálcio (3\%) e cloreto de lítio (2\%), conforme descrito por VINDEROLA \& REINHEIMER [43]. Após homogeneização e endurecimento do ágar, as placas foram incubadas a $37^{\circ} \mathrm{C}$ por três dias em anaerobiose (Sistema de Anaerobiose Anaerogen, Oxoid Ltd., Basingstoke, Reino Unido). As análises microbiológicas foram efetuadas em duplicata.

\subsection{6 - Delineamento experimental e análise estatística}

O delineamento experimental foi inteiramente casualizado, utilizando-se um esquema fatorial 3x4, constituído de 
três tipos de combinações em termos de gomas adicionadas durante a produção dos queijos petit-suisse e de quatro tempos (1, 7, 14 e 21 dias de armazenamento), com duas repetições $[4,14]$.

As diferenças significativas $(\mathrm{p}<0,05)$ para cada parâmetro entre os diferentes tipos de produto e entre os diferentes dias de armazenamento de cada queijo foram determinadas através de análise de variância, utilizando o programa Excel versão 2000 (Microsoft Corporation, USA). As diferenças entre as médias foram detectadas utilizando-se o teste de Tukey.

\section{3 - RESULTADOS E DISCUSSÕES}

\section{1 - Evolução dos parâmetros físico-químicos e microbiológicos}

A Tabela 2 apresenta os resultados de $\mathrm{pH}$, umidade e viabilidade das bactérias probióticas Bifidobacterium longum e Lactobacillus acidophilus durante o armazenamento dos queijos a $4 \pm 1^{\circ} \mathrm{C}$.

Os valores de pH diminuíram ao longo do período de armazenamento para todas as formulações. Houve pequena, porém significativa redução do $\mathrm{pH}$ entre o $1^{\circ}$ e o $7^{\circ}$ dia de armazenamento para todas as formulações $(\mathrm{p}<0,05)$. Uma segunda diminuição significativa do $\mathrm{pH}$ $(\mathrm{p}<0,05)$ foi observada aos 14 dias de armazenamento para a formulação F2 e aos 21 dias de armazenamento para F1 e F3 (Tabela 2).

A quantidade de ácido lático produzida pela cultura starter e pelas culturas probióticas influenciaram na redução de $\mathrm{pH}$ dos queijos petit-suisse estudados, fenômeno este normalmente observado em laticínios adicionados dessas culturas [13]. No entanto, conforme esperado, não houve diferença significativa $(\mathrm{p}>0,05)$ entre os valores de $\mathrm{pH}$ para as diferentes formulações em um mesmo período de armazenamento. Isso pode ser explicado, uma vez que as formulações diferiram somente na composição das gomas utilizadas. Ou seja, ingredientes que influenciam o pH do produto final e ao longo de seu armazenamento, como os tipos e proporções de culturas empregadas e a proporção de polpa, foram mantidos constantes para todas as formulações. Pelo mesmo motivo, também não é esperada diferença significativa entre as formulações com relação à variação das populações dos microrganismos probióticos e dos valores de umidade.

Os valores de umidade foram praticamente constantes e não foram detectadas diferenças significativas ( $p>0,05)$ quando as diferentes formulações foram comparadas em um mesmo período de armazenamento, com exceção de F3, aos sete dias $(\mathrm{p}<0,05)$ conforme mostrado na Tabela 2. O aumento, mesmo significativo, da umidade após 21 dias de armazenamento de F1 e F3 $(\mathrm{p}<0,05)$ para comparações entre os períodos de armazenamento de uma mesma formulação somente pode ser explicado por diferenças amostrais, uma vez que as embalagens de todos os produtos encontravam-se devidamente seladas.

Observando-se o comportamento das culturas probióticas Lactobacillus acidophilus e Bifidobacterium longum (Tabela 2), constatou-se que, durante todo o período de armazenamento, as contagens foram sempre superiores a $6 \log \mathrm{UFC} / g$, concentração mínima requerida para efeito probiótico [16]. B. longum apresentou contagens mais elevadas, sempre acima de 7 log UFC/g, mantendo-se estáveis durante o armazenamento, assim como L. acidophilus, embora uma diferença significativa entre o primeiro dia de armazenamento e o $14^{\circ}$ dia para as contagens de B. longum dos queijos F1 tivesse sido detectada $(\mathrm{p}<0,05)$. Entretanto, essa variação foi mínima (apenas 0,06 log).

Segundo LOURENS-HATTINGH \& VILJOEN [24], a sobrevivência de bactérias probióticas em produtos lácteos fermentados depende, entre vários fatores, do $\mathrm{pH}$ e da temperatura. LANKAPUTHRA \& SHAH [21] observaram maior estabilidade de L. acidophilus nas mesmas condições de

TABELA 2 - Evolução dos parâmetros físico-químicos* (pH e umidade) e das populações de probióticos* dos queijos petit-suisse F1,

F2 e F3 durante o seu armazenamento a $4 \pm 1^{\circ} \mathrm{C}$ por até 21 dias

\begin{tabular}{|c|c|c|c|c|c|}
\hline \multirow{2}{*}{ Formulação } & \multirow{2}{*}{ Dias } & \multirow{2}{*}{$\mathrm{pH}$} & \multirow{2}{*}{ Umidade } & \multicolumn{2}{|c|}{ Contagem de probióticos (log UFC/g) } \\
\hline & & & & L. acidophilus & B. longum \\
\hline \multirow[t]{3}{*}{ F1 } & 1 & $4,72(0,11)^{\mathrm{Aa}}$ & $70,48(0,66)^{\mathrm{Aa}}$ & $6,54(0,06)^{\mathrm{Aa}}$ & $7,46(0,02)^{\mathrm{Aa}}$ \\
\hline & 7 & $4,46(0,02)^{A b}$ & $70,99(0,14)^{\mathrm{Aa}}$ & $6,41(0,13)^{\mathrm{Aa}}$ & $7,42(0,03)^{\text {Aab }}$ \\
\hline & 21 & $4,37(0,06)^{\mathrm{Ac}}$ & $71,46(0,34)^{\mathrm{Ab}}$ & $6,45(0,06)^{\mathrm{Aa}}$ & $7,36(0,04)^{\mathrm{Ab}}$ \\
\hline \multirow[t]{3}{*}{ F2 } & 1 & $4,74(0,09)^{\text {Аa }}$ & $70,36(1,02)^{\mathrm{Aa}}$ & $6,51(0,10)^{\mathrm{Aa}}$ & $7,42(0,05)^{\mathrm{Aa}}$ \\
\hline & 7 & $4,49(0,01)^{A b}$ & $70,83(0,14)^{\mathrm{Aa}}$ & $6,44(0,08)^{\mathrm{Aa}}$ & $7,42(0,04)^{\mathrm{Aa}}$ \\
\hline & 21 & $4,38(0,06)^{\mathrm{Ac}}$ & $71,44(0,77)^{\mathrm{Aa}}$ & $6,47(0,10)^{\mathrm{Aa}}$ & $7,36(0,03)^{\mathrm{Aa}}$ \\
\hline \multirow[t]{4}{*}{ F3 } & 1 & $4,75(0,08)^{\mathrm{Aa}}$ & $70,15(0,75)^{\text {Aa }}$ & $6,48(0,07)^{\mathrm{Aa}}$ & $7,36(0,06)^{\text {Aa }}$ \\
\hline & 7 & $4,49(0,01)^{\mathrm{Ab}}$ & $70,51(0,28)^{\mathrm{Ba}}$ & $6,47(0,08)^{\mathrm{Aa}}$ & $7,43(0,01)^{\mathrm{Aa}}$ \\
\hline & 14 & $4,49(0,03)^{A b c}$ & $70,43(0,49)^{\mathrm{Aa}}$ & $6,41(0,10)^{\mathrm{Aa}}$ & $7,41(0,04)^{\mathrm{Aa}}$ \\
\hline & 21 & $4,41(0,05)^{\mathrm{Ac}}$ & $71,20(0,60)^{\mathrm{Ab}}$ & $6,47(0,04)^{\mathrm{Aa}}$ & $7,37(0,03)^{\mathrm{Aa}}$ \\
\hline
\end{tabular}

*Médias (e respectivos desvios-padrão entre parênteses)

A, B - Para cada coluna, letras maiúsculas sobrescritas diferentes indicam diferenças significativas (p<0,05) obtidas entre as formulações estudadas para um mesmo período de incubação

a, b - Para cada coluna, letras minúsculas sobrescritas diferentes indicam diferenças significativas ( $<<0,05)$ obtidas entre os diferentes períodos de armazenamento de cada uma das formulações estudadas 
$\mathrm{pH}(4,37$ a 4,66$)$ e temperatura de armazenamento $\left(4\right.$ a $\left.5^{\circ} \mathrm{C}\right)$ empregadas no produto desenvolvido no presente trabalho.

A viabilidade de L. acidophilus e B. longum não sofreu influência da redução significativa do $\mathrm{pH}$ durante o armazenamento dos queijos petit-suisse. L. acidophilus apresenta $\mathrm{pH}$ ótimo de multiplicação ao redor de 5,5 a 6,0 [13], sendo bastante resistente ao armazenamento em baixas temperaturas [24]. No presente trabalho, devido a essa resistência ao armazenamento refrigerado, a sobrevivência de $L$. acidophilus foi alta, embora o $\mathrm{pH}$ do produto se encontrasse abaixo do pH ótimo de multiplicação desse microorganismo. No entanto, desde o início, as contagens de L. acidophilus foram menores (aproximadamente 1 ciclo log) que as apresentadas por B. longum. Portanto, seria necessário aumentar a percentagem da cultura de L. acidophilus adicionada ao leite para a obtenção de resultados mais favoráveis, próximos aos obtidos pelo $B$. longum, no produto final.

As bifidobactérias são microrganismos mais sensíveis aos valores de $\mathrm{pH}$ do produto ( $\mathrm{pH}$ ótimo entre 6,0 e 7,0 ) [13] e são menos tolerantes ao armazenamento refrigerado [24]. Segundo LOURENS-HATTINGH \& VILJOEN [24], B. longum apresenta crescimento diminuído em laticínios, pois requer condições especiais para sobrevivência e por isso é mais sensível a tais condições. No entanto, B. longum apresentou elevada viabilidade nos queijos petit-suisse elaborados no presente trabalho.

\section{2 - Evolução do perfil de textura instrumental}

A legislação brasileira permite que cada espessante seja empregado na proporção máxima de 0,50\% da massa total de queijo petit-suisse [5]. Essa percentagem é muito baixa para garantir a textura adequada do produto, uma vez que cada goma utilizada isoladamente não apresentaria poder suficiente para fornecer a consistência desejada ao queijo petit-suisse [25]. Dessa forma, decidiu-se utilizar combinações com mais de uma goma, permitindo, assim, aumentar a percentagem total de espessante.

Os resultados das amostras analisadas quanto à textura são apresentados na Tabela 3.

Para todos os parâmetros de textura estudados, houve diferenças significativas entre as formulações $\mathrm{F} 1$, F2 e F3 $(\mathrm{p}<0,05)$ ao longo de todo o armazenamento, com valores de firmeza sempre mais elevados para F1, seguidos de F2 (Tabela 3 ).

Somente F1 não apresentou diferenças significativas quanto à firmeza $(\mathrm{p}>0,05)$ durante o período de armazenamento de 21 dias (Tabela 3). Dessa forma, para esse parâmetro, F1 foi considerada a formulação mais estável, ou seja, a mais adequada de acordo com os objetivos deste trabalho. No entanto, observando os valores médios de firmeza obtidos, é possível perceber que tanto F2 como F3 não apresentaram grande variação para esse atributo (Tabela 3). A estabilidade da firmeza durante o período de armazenamento é desejada, uma vez que, dessa forma, confirma-se que o produto após algumas semanas de armazenamento continua semelhante ao produto recém-fabricado. A estabilidade é muito desejada para manter as características fisico-químicas e, conseqüentemente, sensoriais, do início ao fim da vida de prateleira do produto.

Uma explicação possível para a manutenção dos valores altos de firmeza de F1 durante todo o armazenamento seria a combinação entre maior quantidade de goma xantana com o menor teor de goma carragena, em comparação a F2 e F3. CARDARELLI et al. [9] observaram um aumento significativo da firmeza ao longo de 28 dias de armazenamento a $4^{\circ} \mathrm{C}$ de duas formulações queijo petit-suisse simbiótico, em que a goma xantana foi adicionada como estabilizante. Por outro lado, em testes preliminares no presente estudo, verificou-se uma diminuição da firmeza ao longo do armazenamento nos queijos petit-suisse adicionados de goma carragena [25].

TABELA 3 - Evolução dos parâmetros de textura* dos queijos petit-suisse $\mathrm{F} 1, \mathrm{~F} 2$ e F3 durante o seu armazenamento a $4 \pm 1^{\circ} \mathrm{C}$ por até 21 dias

\begin{tabular}{|c|c|c|c|c|c|c|}
\hline Formulação & Dias & Firmeza (gf) & Adesividade (gfs) & Elasticidade & Coesividade & Gomosidade (gf) \\
\hline \multirow[t]{4}{*}{ F1 } & 1 & $170,8(8,71)^{\mathrm{Aa}}$ & $-248,3(17,89)^{\mathrm{Aa}}$ & $0,860(0,003)^{A a}$ & $0,368(0,008)^{\mathrm{Aa}}$ & $63,27(5,20)^{A a}$ \\
\hline & 7 & $167,0(0,84)^{\mathrm{Aa}}$ & $-292,1(8,73)^{A b}$ & $0,874(0,004)^{A b}$ & $0,351(0,010)^{A b}$ & $60,26(1,25)^{\mathrm{Aa}}$ \\
\hline & 14 & $171,0(5,20)^{\mathrm{Aa}}$ & $-304,8(10,52)^{A b}$ & $0,887(0,007)^{A c}$ & $0,344(0,002)^{A b}$ & $59,24(2,53)^{\mathrm{Aa}}$ \\
\hline & 21 & $163,1(4,76)^{\mathrm{Aa}}$ & $-325,7(13,90)^{A c}$ & $0,887(0,002)^{A c}$ & $0,340(0,002)^{A c}$ & $56,10(1,76)^{A b}$ \\
\hline \multirow[t]{4}{*}{$\mathrm{F} 2$} & 1 & $85,9(1,42)^{\mathrm{Ba}}$ & $-209,7(15,92)^{\mathrm{Ba}}$ & $0,877(0,004)^{\mathrm{Ba}}$ & $0,452(0,002)^{\mathrm{Ba}}$ & $39,13(0,64)^{\mathrm{Ba}}$ \\
\hline & 7 & $100,2(6,37)^{\mathrm{Bb}}$ & $-270,8(33,66)^{\mathrm{Bb}}$ & $0,883(0,004)^{\mathrm{Ba}}$ & $0,424(0,002)^{\mathrm{Bb}}$ & $42,83(3,52)^{\mathrm{Bb}}$ \\
\hline & 14 & $108,6(2,95)^{\mathrm{Bc}}$ & $-305,4(27,83)^{\mathrm{Bbc}}$ & $0,883(0,013)^{\mathrm{Ba}}$ & $0,409(0,013)^{\mathrm{Bc}}$ & $45,08(2,54)^{\mathrm{Bbc}}$ \\
\hline & 21 & $114,5(5,04)^{B d}$ & $-317,5(29,93)^{\mathrm{Bc}}$ & $0,884(0,005)^{\mathrm{Ba}}$ & $0,407(0,008)^{\mathrm{Bc}}$ & $49,19(4,20)^{\mathrm{Bc}}$ \\
\hline \multirow[t]{4}{*}{ F3 } & 1 & $31,49(0,99) \mathrm{Ca}$ & $-39,36(5,78) \mathrm{Ca}$ & $0,881(0,007)^{C a b}$ & $0,593(0,018)^{\mathrm{Ca}}$ & $18,38(0,64)^{\mathrm{Ca}}$ \\
\hline & 7 & $37,70(0,61)^{\mathrm{Cb}}$ & $-63,25(3,60)^{\mathrm{Cb}}$ & $0,885(0,009)^{\mathrm{Ca}}$ & $0,461(0,010)^{\mathrm{Cb}}$ & $17,94(0,74)^{\mathrm{Ca}}$ \\
\hline & 14 & $39,80(1,18)^{\mathrm{Cc}}$ & $-64,75(1,17)^{\mathrm{Cb}}$ & $0,869(0,011)^{\mathrm{cb}}$ & $0,454(0,019)^{\mathrm{Cbc}}$ & $18,34(0,60)^{\mathrm{Ca}}$ \\
\hline & 21 & $40,09(0,50) \mathrm{Cc}$ & $-68,09(3,01)^{\mathrm{Cc}}$ & $0,899(0,007)^{\mathrm{cc}}$ & $0,444(0,013)^{\mathrm{cc}}$ & $18,12(0,25)^{\mathrm{Ca}}$ \\
\hline
\end{tabular}

*Médias (e respectivos desvios-padrão entre parênteses)

A, B - Para cada coluna, letras maiúsculas sobrescritas diferentes indicam diferenças significativas ( $p<0,05)$ obtidas entre as formulações estudadas para um mesmo período de incubação

a, b - Para cada coluna, letras minúsculas sobrescritas diferentes indicam diferenças significativas $(\mathrm{p}<0,05)$ obtidas entre os diferentes períodos de armazenamento de cada uma das formulações estudadas 
Ao empregar ambas em uma mesma formulação, as variabilidades de aumento e diminuição de firmeza durante o armazenamento, que seriam observadas com cada goma utilizada separadamente, foram equilibradas nas proporções empregadas em F1. O emprego de menor quantidade de goma xantana em F2 ou a ausência dessa goma em F3 resultou em menor firmeza comparada a F1. Segundo HUANG et al. [17], a goma xantana apresenta maior viscosidade aparente, seguida das gomas guar e pectina. Dessa forma, a maior firmeza obtida para as formulações F1 e F2, contendo a goma xantana, ocorreu conforme seria esperado.

De modo semelhante ao observado para firmeza, verificou-se que os maiores valores de adesividade foram obtidos (em módulo) para F1 (Tabela 3). No entanto, houve aumento significativo da adesividade para todas as formulações durante o armazenamento $(\mathrm{p}<0,05)$.

Houve aumento da elasticidade durante o armazenamento de F1, F2 e F3, não sendo significativo (p>0,05) somente para F2. Aparentemente, esse aumento da elasticidade ocorreu independente dos demais parâmetros de textura. Os valores médios mais elevados de elasticidade foram observados em F3, seguida por F2 e F1 (Tabela 3).

A coesividade diminuiu significativamente $(\mathrm{p}<0,05)$ ao longo do armazenamento para todas as formulações (Tabela 3). Os menores valores de coesividade foram observados em F1, enquanto que os maiores foram verificados em F3. Mesmo visualmente, era possível verificar a maior coesividade de F3. É possível que os valores de coesividade dos queijos petit-suisse analisados estejam inversamente relacionados com os valores de firmeza, uma vez que a maior coesividade esteve relacionada à menor firmeza e vice-versa.

F1 apresentou gomosidade decrescente durante o armazenamento, com diminuição significativa somente aos 21 dias de armazenamento ( $\mathrm{p}<0,05)$. De modo semelhante à firmeza, a gomosidade em F2 apresentou-se significativamente crescente $(\mathrm{p}<0,05)$ durante o armazenamento. Por outro lado, a gomosidade em F3 manteve-se estável, sem diferenças significativas durante o armazenamento ( $p>0,05)$, resultado diferente do observado para firmeza durante o mesmo período.

Os resultados de textura foram de maior relevância no presente estudo, em que diferentes gomas foram empregadas na elaboração do queijo petit-suisse probiótico, uma vez que, conforme esperado, as contagens microbianas, o $\mathrm{pH}$ e a umidade foram semelhantes para as três formulações de queijo estudadas durante todo o armazenamento.

\section{4 - CONCLUSÕES}

As culturas probióticas de Lactobacillus acidophilus e Bifidobacterium longum mantiveram-se viáveis em concentrações apropriadas para todas as formulações estudadas até o último dia de armazenamento (superiores a $6 \log \mathrm{UFC} / \mathrm{g}$ ), sendo que os melhores resultados foram obtidos por B. longum (superiores a 7 log UFC/g). A di- minuição do $\mathrm{pH}$ das diferentes formulações estudadas durante o armazenamento não influiu na viabilidade das culturas probióticas.

Com base nos parâmetros de textura obtidos, a combinação das gomas xantana, carragena e guar $(2,5: 2,5: 5)$ na formulação F1 foi a que produziu os melhores resultados, contribuindo para a maior estabilidade da firmeza durante todo o armazenamento do produto. Adicionalmente, os valores de gomosidade de F1 diminuíram significativamente somente ao $21^{\circ}$ dia de armazenamento, o que confirma a estabilidade fornecida pela interação entre as gomas utilizadas e os outros ingredientes nessa formulação. Sendo assim, a estabilidade da textura do queijo petit-suisse probiótico foi alcançada com a combinação de gomas empregada em F1, característica esta que resulta na maior qualidade do produto, permitindo ao consumidor adquirir um produto que apresentará as mesmas características durante todo o armazenamento.

\section{5 - REFERÊNCIAS BIBLIOGRÁFICAS}

[1] ALEGRO, J.H.A.; ROCHA, J.S.; SAAD, S.M.I. Viability of Lactobacillus acidophilus and Bifidobacterium lactis in Minas frescal cheese. In: Congreso Latinoamericano de Microbiología e Higiene de los Alimentos, 7, Santiago, Chile, 2002.

[2] ALEXANDER, R.J. Moving toward low-calorie dairy products. Food Product Design, v. 7, n. 1, p. 75 -76, 1997.

[3] ASSOCIAÇÃO BRASILEIRA DAS INDÚSTRIAS DE QUEIJO. Produção brasileira de produtos lácteos em estabelecimentos sob inspeção federal. São Paulo, 2002. [Comunicação].

[4] BARROS NETO, B.; SCARMINIO, I.S.; BRUNS, R.E. Como fazer experimentos: pesquisa e desenvolvimento na ciência e na indústria. Campinas: Unicamp, 2003.

[5] BRASIL. Instrução Normativa n 53 , de 29 de dezembro de 2000. O Ministério de Estado da Agricultura e do Abastecimento aprova o regulamento técnico para fixação de identidade e qualidade de queijo tipo petit-suisse. In: LERAYER, A.L.S. (ed). Nova legislação de produtos lácteos. São Paulo: Fonte, 2002. p. 135-137.

[6] BURITI, F.C.A.; ROCHA, J.S.; ASSIS, E.G.; SAAD, S.M.I. Probiotic potential of Minas fresh cheese prepared with the addition of Lactobacillus paracasei. Lebensm.Wiss. Technol., v. 38, n. 2, p. 173-180, 2005.

[7] BURITI, F.C.A.; ROCHA, J.S.; SAAD, S.M.I. Incorporation of Lactobacillus acidophilus in Minas fresh cheese and its implications for textural and sensorial properties during storage. Int. Dairy J., Amsterdam, v. 15, n. 12, p. 1.279-1.288, 2005.

[8] CÂNDIDO, L.M.B.; CAMPOS, A.M. Alimentos para fins especiais: dietéticos. São Paulo: Varela, 1996.

[9] CARDARELLI, H.R.; FEBBO, C.; SAAD, S.M.I. Monitoramento de parâmetros de textura instrumental em queijo petit-suisse probiótico ao longo de sua vida de prateleira. Rev. Bras. Cienc. Farm., v. 39, supl. 3, p. 147-149, 2003. 
[10] CHA, D.S.; CHOI, J.H.; CHINNAN, M.S.; PARK, H.J. Antimicrobial films based on Na-alginate and $\kappa$-carrageenan. Lebensm.-Wiss. Technol., v. 35, p. 715719, 2002.

[11] FAO/WHO. Evaluation of health and nutritional properties of probiotics in food including powder milk with live lactic acid bacteria. Córdoba, 2001. Disponível em: ftp://ftp.fao.org/docrep/fao/meeting/009/ y6398e.pdf. Acesso em: 6 jun. 2005. [Report of a Joint FAO/WHO Expert Consultation].

[12] GLICKSMAN, M. Food Hydrocolloids. Boca Raton: CRC, 1986. v. 3.

[13] GOMES, A.M.P.; MALCATA, F.X. Bifidobacterium spp. and Lactobacillus acidophilus: biological, biochemical, technological and therapeutical properties relevant for use as probiotics. Trends Food Sci. Technol., v. 10, p. 139-157, 1999.

[14] GOMES, F.P. Curso de estatística experimental. $12^{\text {th }}$ ed. São Paulo: Nobel, 1987.

[15] GUEIMONDE, M.; DELGADO, S.; MAYO, B.; RUAS-MADIEDO, P.; MARGOLLES A.; REYES-GAVILÁN, C.G. Viability and diversity of probiotic Lactobacillus and Bifidobacterium populations included in commercial fermented milks. Food Res. Int., v. 37, p. 839-850, 2004.

[16] HOIER, E.; JANZEN, T.; HENRIKSEN, C.M.; RATTRAY, F.; BROCKMANN, E.; JOHANSEN, E. The production, application and action of lactic cheese starter cultures. In: LAW, B.A. (ed.) Technology of cheesemaking. Boca Raton: CRC, 1999. p. 99-131.

[17] HUANG, X.; KAKUDA, Y.; CUI, W. Hydrocolloids in emulsions: particle size distribution and interfacial activity. Food Hydrocolloids, v. 15, p. 533-542, 2001.

[18] HUNT, C.C.; MAYNES, J.R. Current issues in the stabilization of culture dairy products. J. Dairy Sci., v. 80, p. 2.639-2.643, 1997.

[19] INTERNATIONAL DAIRY FEDERATION. Fermented and non-fermented milk products. Detection and enumeration of Lactobacillus acidophilus. Culture media. Brussels: International Dairy Federation, 1995. [Bulletin of the IDF, 306]

[20] KATZBAUER, B. Properties and applications of xanthan gum. Polymer Degradation and Stability, v. 59, p. 81-84, 1998.

[21] LANKAPUTHRA, W.E.V.; SHAH, N.P. Survival of Lactobacillus acidophilus and Bifidobacterium species in the presence of acid and bile salts. Cultured Dairy Products Journal, v. 30, n. 3, p. 113-118, 1995 apud. LOURENSHATTINGH, A., VILJOEN, B.C. Yogurt as probiotic carrier food. Int. Dairy J., v. 11, p. 1-17, 2001.

[22] LEE, Y.K.; SALMINEN, S. The coming of age of probiotics. Trends Food Sci. Technol., v. 6, p. 241-245, 1995.

[23] LETHUAUT, L.; BROSSARD, C.; ROUSSEAU, F.; BOUSSEAU, B.; GENOT, C. Sweetness-texture interactions in model dairy desserts: effect of sucrose concentration and the carrageenan type. Int. Dairy J., v. 13, n. 8, p. 631-641, 2003.

[24] LOURENS-HATTINGH, A.; VILJOEN, B.C. Yogurt as probiotic carrier food. Int. Dairy J., v. 11, p. 1-17, 2001.

[25] MARUYAMA, L.Y.; FEBBO, C.; CARDARELLI, H.R.; SAAD, S.M.I. Avaliação de textura em queijo tipo petit-suisse probiótico. Trabalho não publicado, Departamento de Tecnologia Bioquímico-Farmacêu- tica, Faculdade de Ciências Farmacêuticas, USP, São Paulo, 2004.

[26] MATTILA-SANDHOLM, T.; MYLLÄRINEN, P.; CRITTENDEN, R.; MOGENSEN, G.; FONDÉN, R.; SAARELA, M. Technological challenges for future probiotic foods. Int. Dairy J., v. 12, p. 173-182, 2002.

[27] MUNHOZ, M.P.; WEBER, F.H.; CHANG, Y.K. Influência de hidrocolóides na textura de gel de amido de milho. Ciênc. Tecnol. Aliment., v. 24, n. 3, p. 403-406, 2004.

[28] OKAZAKI, T.Y.; ALEGRO, J.H.A.; ROCHA, J.S.; SAAD, S.M.I. Microbiological profile of probiotic Minas cheese. In: Congresso Brasileiro de Microbiologia, 21, Foz do Iguaçu, 2001. Resumos. Rio de Janeiro: Sociedade Brasileira de Microbiologia, 2001. p. 389.

[29] OLIVEIRA, M.N.; SIVIERI, K.; ALEGRO, J.H.A.; SAAD, S.M.I. Aspectos tecnológicos de alimentos funcionais contendo probióticos. Rev. Bras. Cienc. Farm., v. 38, n. 1, p. 1-21, 2002.

[30] PENNA, A.L.B. Efeito das gomas carragena, guar e xantana sobre as características reológicas e sensoriais de bebidas lácteas a base de iogurte e de soro. São Paulo, 1999, 328 p. Tese de doutorado, Departamento de Tecnologia Bioquímico-Farmacêutica, Faculdade de Ciências Farmacêuticas, Universidade de São Paulo (USP).

[31] ROCHA, J.S.; ALEGRO, J.H.A.; SAAD, S.M.I. Microbiological profiles of probiotic Minas frescal cheese manufactured with the addition of Lactobacillus acidophilus. In: Congreso Latinoamericano de Microbiología e Higiene de los Alimentos, 7, Santiago, Chile, 2002.

[32] SANDERS, M.E. Probiotics: considerations for human health. Nutr. Rev., v. 61, n. 3, p. 91-99, 2003.

[33] SANDRAZ, M.H. Fromage Frais: le bénéfice de l'inovation. Revue Laitiere Française, n. 486, p. 26-30, 1989.

[34] SCHMIDT, K.A.; SMITH, D.E. Rheological properties of gum and milk protein interactions. J. Dairy Sci., v. 75, p. 36-42, 1992.

[35] SHOEMAKER, C.F.; NANTZ, J.; BONNANS, S.; NOBLE, A.C. Rheological characterization of dairy products. Food Technol., v. 46, n. 1, p. 98-104. 1992.

[36] SPAGNUOLO, P.A.; DALGLEISH, D.G.; GOFF, H.D.; MORRIS, E.R. Kappa-carrageenan interactions in systems containing casein micelles and polysaccharide stabilizers. Food Hydrocolloids, v. 19, p. 371-377, 2005.

[37] STANTON, C.; DESMOND, C.; COAKLEY, M.; COLLINS, J.K.; FITZGERALD, G.; ROSS, R.P. Challenges facing development of probiotic-containing functional foods. In: FARNWORTH, E.R. (ed). Handbook of fermented functional foods. Boca Raton: CRC, 2003. p. 27-58.

[38] STANTON, C.; GARDINER, G.; MEEHAN, H.; COLLINS, K.; FITZGERALD, G.; LYNCH, P.B.; ROSS, R.P. Market potential for probiotics. Am. J. Clin. Nutr., v. 73, n. 2, p. 476S-483S, 2001.

[39] TEJADA-SIMON, M.V.; LEE, J.H.; USTUNOL, Z.; PESTKA, J.J. Ingestion of yogurt containing Lactobacillus acidophilus and Bifidobacterium to potentiate immunoglobulin A responses to cholera toxin in mice. J. Dairy Sci., v. 82, p. 649-660, 1999. 
[40] THEBAUDIN, J.Y.; LEFEBVRE ,A.C.; HARRINGTON, M.E; BOURGOIS, C.M. Dietary fibres: nutritional and technological interest. Trends Food Sci. Technol., v. 8, n. 2, p. 41-48, 1997.

[41] VEIGA, P.G.; CUNHA, R.L.; VIOTTO, W.H.; PETENATE, A.J. Caracterização química, reológica e aceitação sensorial de queijo petit-suisse brasileiro. Ciênc. Tecnol. Aliment., v. 20, n. 3, p. 349-357, 2000.

[42] VINDEROLA, C.G.; PROSELLO, W.; GHIBERTO, D.; REINHEIMER, J.A. Viability of probiotic (Bifidobacterium, Lactobacillus acidophilus and Lactobacillus casei) and nonprobiotic microflora in Argentinian fresco cheese. J. Dairy Sci., v. 83, n. 9, p. 1.905-1.911, 2000.

[43] VINDEROLA, C.G.; REINHEIMER, J.A. Culture media for the enumeration of Bifidobacterium bifidum and Lactobacillus acidophilus in the presence of yoghurt bacteria. Int. Dairy J., v. 9, p. 497-505, 1999.

[44] WANG, Y.C.; YU, R.C.; CHOU, C.C. Viability of lactic acid bacteria and bifidobacteria in fermented soymilk after drying, subsequent rehydratation and storage. Int. J. Food Microbiol., v. 93, n. 2, p. 209-217, 2004.

[45] YANES, M.; DURÁN, L.; COSTELL, E. Effect of hydrocolloid type and concentration on flow behaviour and sensory properties of milk beverages model systems. Food Hydrocolloids, v. 16, p. 605-611, 2002.

\section{6 - AGRADECIMENTOS}

Os autores agradecem à Fundação de Amparo à Pesquisa do Estado de São Paulo (Fapesp) (Processos 03/13748-1, 02/14185-8, 02/11294-0 e 04/13597-6), ao Conselho Nacional de Desenvolvimento Científico e Tecnológico (CNPq) e à Coordenação de Aperfeiçoamento de Pessoal de Nível Superior (CAPES) pelo auxílio financeiro e bolsas. Os autores agradecem, também, às empresas Leite Salute, Plury Química, Mylner, Danisco, Avebe, CP Kelco e Rhodia pelo fornecimento do leite, corante, aroma, culturas e gomas empregados na pesquisa. 